\title{
Correlation of ink viscosity and printability in offset lithography process on paperboard used in packaging
}

\author{
Madhura P. Mahajan', Swati Bandyopadhyay² \\ ${ }^{1}$ Department of Printing Engineering, Pune Vidyarthi Griha's College of Engineering and Technology Parvati, \\ Pune Maharashtra, India \\ 2 Department of Printing Engineering, Jadavpur University, Kolkata, India \\ Corresponding author: Madhura P. Mahajan, madhuramahajan72@gmail.com
}

\begin{abstract}
In the recent years, the demands for offset inks with better flow ability and viscosity have risen higher with the improvements of printing techniques. To ensure uniformity in printability sheet after sheet it is very important to maintain certain print conditions for that print job as approved by customers and use this data for future reference of printing. The quality of offset printing process depends on many chemical and physical specifications of the materials and components involved in the process. Most important being printing inks and its rheology. In this work, three process color cyan inks have been formulated with varying levels of viscosity with use of certain rheology modifiers. Trials on the printing machine were conducted using a systematic layout of test elements on a fully automatic offset lithography printing machine using a Solid Bleached Sulphite Board (SBS) and the print results were correlated to rheological parameters such as viscosity and thixotropy. The tone value increase (TVI) was measured and was correlated to viscosity and index of thixotropy. Higher viscosity yields lower dot gain and better color reproducibility. A mathematical relation has been established between ink viscosity, dot area and tone value increase. As the demands for packaging increases, the study about the ink rheology and its effect on print performance can help printers and ink manufacturers with better ink formulations to achieve precise print results.
\end{abstract}

Keywords: Ink viscosity, Tone Value Increase (TVI), Shear Stress, Dot area

\section{Introduction}

Offset lithography print process is the most common and most widely used process for printing on various paper and paperboards and is widely used to print on higher grammage paperboard used for cartons or box making. A continuous tone photograph or image is reproduced in a print process with help of halftone dots of varying sizes to represent the variations in visual impression of lightness or darkness. Printing by offset lithography is governed by number of factors. A change in any of the factors results into a change in the print parameters [1]. The layout, design and color reproductions for a carton or packaging box form crucial basis for acceptance or rejection of the cartons. Solid ink density (SID), tone value increase (TVI) and color are some of the important response factors for quality control in printing. Dot area has the size of ink area per unit printing area with unit of percent (\%). There are two reasons for increase in dot size of the halftone: impact of the mechanical action during the ink transfer between printing cylinders and other is due to the scattering of light beneath the dot that results into higher color intensity coming from them [2]. Physical dot gain is a characteristic of its process or due to raw material in the ink that causes change in the flow properties. Understanding and calculating physical extension of dot from its nominal value can be useful to calibrate printing presses for halftoning [3]. This work covers the mechanical part of tone value 
increase due to one of the important raw material in the print process which is ink. Printing is the application of a thin film of a dye or pigment dispersion in liquid with desired viscosity to paper or polymer film [4]. As the concentration of ink increases, the flocculated nature also increases that results into high shear thinning which occurs due to interparticle attraction [5]. Inks with higher concentration of pigments are short inks having shorter ink filament size and possess higher yield value. With good rheology, it helps in better transfer down rollers [6]. The rheological properties including viscosity, thixotropy and viscoelasticity are contributing factors in determining the quality. At lower shear rates, viscosity decreases and reaches a plateau which is termed as zero shear viscosity $\left(\eta_{0}\right)$. Due to breakage of flocs at high shear, orientation of molecules and non-spherical shape of particles in ink dispersions, viscosity approaches another plateau named infinite shear viscosity $\left(\eta_{\infty}\right)$. The ink transfer on the printing machines is controlled by infinite shear viscosity, as the particle flocs present in the inks segregate at high shear rate. The hysteresis loop is another important parameter to evaluate thixotropic nature of materials. Dot spread resulting into TVI occurs if thixotropy is too weak and it is difficult to transfer ink if thixotropy is too strong [7]. Many printing processes including screen printing especially using silver paste also recommend higher viscosity during printing which resulted into better print resolution [8]. Color changes in print result can be attributable to changes in ink viscosity rather than process parameters [9]. Previous research shows a number of rheological models being fitted to the flow curves of inks. Bingham model used to fit flow curves of emulsified inks and un-emulsified inks [10. The experiments of shear stress and shear rate was also studied using Bingham Exponential Decrease model in which they studied the rheological properties of highly pigmented inks at different temperatures [11]. The effect of decreasing shear rate and increasing shear rates on viscosity and parameters such as zero shear viscosity and infinite shear viscosity was studied using the Carreau model [12]. Casson model was used to evaluate the flow behavior of emulsified and unemulsified offset inks by rotational tests. The yield point, viscosity at infinite shear rate were calculated by the Casson equation in their work [13]. In the offset print process the splitting of ink film occurs with the help of rollers rotating at same speed which is governed by phenomenon of shear thinning and viscoelasticity [11]. Ink splitting on the rollers is an interesting phenomenon. The passage of ink takes place between every two rollers in contact. As the rollers rotate the ink film is forced from the entry side of the nip contact of the rollers due to high pressure. But due to pressure lower than atmospheric pressure at the exit side of the nip, cavitation occurs and splits the film of ink into small filaments [14]. Previous work deals with study of viscoelastic behavior due to varying levels of binder polymers, pigments and various rheology modifying additives added in inks. Stress sweep was conducted in the dynamic test and higher critical stress indicated a stronger structure of the inks [15]. The rate of breakdown and rate of build-up during the up and downcurves respectively play a significant role especially in printing inks where it is important that the inks should have a slow rate of breakdown on the rollers and faster build-up on paper after printing [16]. As the viscosity of ink increases, in our case due to the addition of additives like fumed silica, the cohesive force increases and so does the thixotropy of the ink [17]. Yield stress is the minimum stress required for the ink to flow. Below this stress the material is purely elastic [18]. It is an important characteristic which explains the structure of the ink. Higher viscosity has higher yield stress, thus giving a stronger network structure to the ink [19]. Oscillating strain or stress is applied and corresponding stress or strain is measured. Dynamic strain sweeps are usually carried out from 0.1 to $100 \%$. The strain sweep helps to check the strain \% at which the material behaves linearly. Oscillatory tests are done over a range of frequency [20] [21]. Printing inks are subjected to high shear rates during the printing operation. These shear forces develop high shear stresses. Hence it is necessary to characterize the inks for their behavior on the printing presses [22]. Clay thickeners and fumed silica are added to inks to increase yield and viscosity of inks [24]. Use of clay in inks gives smoothness and gloss due to their good rheology [29]. Offset inks are dispersions 
having high viscosity. The solid part of inks comprises of pigments which constitutes 10$20 \%$ by weight, resins $20-40 \%$ by weight, dispersed in an oil-based medium which usually constitutes $30-50 \%$ by weight. Additives such as waxes, plasticizers are added to $10 \%$ by weight [32].

A lot of work has been done on the chemical and physical behavior of inks. But very less has been done on the effect of rheology and flow of ink on the print behavior in terms of dot gain and color etc. The objective of this work is to characterize the inks' rheological properties and correlate it to print parameters such as dot gain.

\section{Experimental Methods and Materials}

\subsection{Material}

\subsubsection{Ink}

Pigments, resins and solvent influence the final properties of inks [23]. Phthalocyanine Blue Alpha Form Pigment Blue 15 CAS No.147-148 ink was used for the experimentation purpose. Typical recipe of offset inks comprises of pigments dispersed in a vehicle system of resins, solvents, additives and waxes and their drying occurs by oxidation process and by penetration process. Mineral Oil CAS No.
64741-91-9 and Rosin Modified Phenolic Resin has been used in the inks. The composition of flow improver used in different percent is castor oil ester. The base ink composition as in Fig. 1 has been modified to obtain variation in the viscosities of the 3 inks and they were further analysed for their flow behavior and print results.

Table 1 Base inks modified to achieve different flow properties

\begin{tabular}{|l|c|c|c|}
\hline Raw Material & $\begin{array}{c}\text { Ink } \\
\text { sample 1 }\end{array}$ & $\begin{array}{c}\text { Ink } \\
\text { sample 2 }\end{array}$ & $\begin{array}{c}\text { Ink } \\
\text { Sample 3 }\end{array}$ \\
\hline Base Ink (100\%) & 100.00 & 100.00 & 100.00 \\
\hline Fumed Silica (\%) & 0.00 & 0.00 & 5.00 \\
\hline Clay Thickener (\%) & 0.00 & 3.00 & 1.00 \\
\hline Mineral Oil (\%) & 0.75 & 1.00 & 2.00 \\
\hline Flow Improver (\%) & 0.00 & 0.50 & 0.90 \\
\hline
\end{tabular}

Rheology modifiers such as fumed silica, clay thickener, mineral oil and a flow improver were added in percent to the base ink as given in Fig. (1) in proportions given in Table (1). The viscosity at the lab during making of the inks was measured by Larray Viscometer and the results are given Table (2).

Table 2 Ink viscosities measured by Larray Viscometer measured during ink manufacturing

\begin{tabular}{|l|c|c|c|}
\hline Ink sample & 1 & 2 & 3 \\
\hline Viscosity [Pa·s] & 15 & 25 & 45 \\
\hline
\end{tabular}

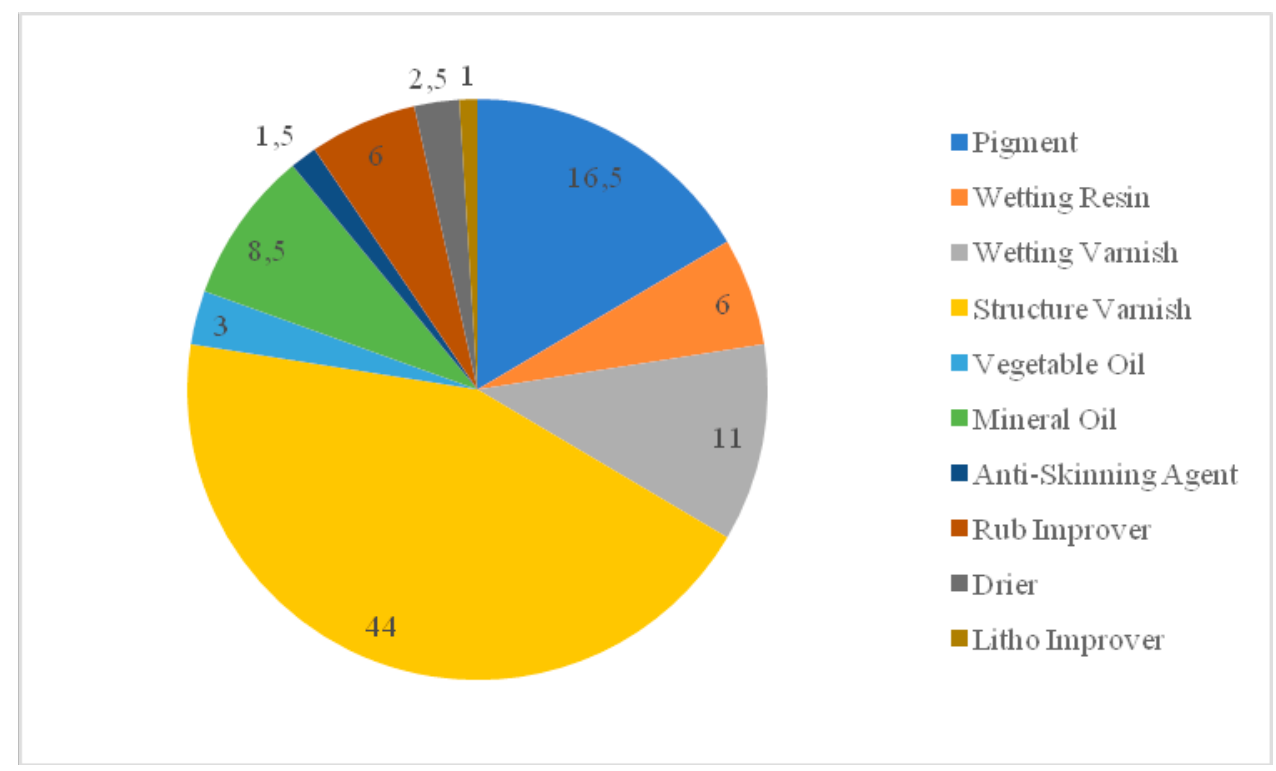

Fig. 1 Constituents(percent) of base ink 


\subsubsection{Characteristics of SBS paperboard}

Printing trials were conducted on solid bleached sulphate boards (SBS) virgin fibre grade of paperboard of 300 grams per metre square $\left(\mathrm{g} / \mathrm{m}^{2}\right)$. The various optical such as CIE
Whiteness, ISO Brightness, ISO Opacity, color of paper was measured in terms of CIELAB and physical properties of the SBS paperboard such as PPS Roughness, stiffness were measured. The values are presented in table 3 .

Table 3 Characteristics of SBS paperboard used for print trials

\begin{tabular}{|c|c|c|c|c|c|c|c|c|c|c|}
\hline \multirow[t]{2}{*}{$\begin{array}{c}\text { CIE } \\
\text { Whiteness } \\
(\%)\end{array}$} & \multirow[t]{2}{*}{$\begin{array}{c}\text { ISO } \\
\text { Brightness } \\
(\%)\end{array}$} & \multirow[t]{2}{*}{$\begin{array}{c}\text { ISO } \\
\text { Opacity } \\
(\%)\end{array}$} & \multirow[t]{2}{*}{$\begin{array}{l}\text { Porometrique } \\
\text { density value }\end{array}$} & \multirow[t]{2}{*}{$\mathrm{pH}$} & \multicolumn{3}{|c|}{ CIE LAB } & \multirow[t]{2}{*}{$\begin{array}{c}\text { PPS } \\
\text { Roughness } \\
(\mu \mathrm{m})\end{array}$} & \multicolumn{2}{|c|}{$\begin{array}{c}\text { L\& W Bending } \\
\text { Resistance } \\
(\mathrm{mN})\end{array}$} \\
\hline & & & & & $\mathrm{L}^{*}$ & $a^{*}$ & $b^{*}$ & & M.D & C.D \\
\hline 129.06 & 94.57 & 99.89 & 0.32 & 7.4 & 94.75 & 1.86 & -10.58 & 1.05 & 428 & 205 \\
\hline
\end{tabular}

\subsection{Rheological Tests of Inks}

Rheology of 3 commercial offset inks supplied by Huber Group (India) was measured using a rheometer. The rheological measurements were performed using a control-shear stress (CSS) rheometer PHYSICA MCR 301 made by Anton Paar with cone and plate (CP50) geometry (cone radius: $R=25 \mathrm{~mm}$; cone angle: $\alpha=1^{\circ}$ ) as shown in Fig. 2. All tests were carried out at $28^{\circ} \mathrm{C}$. A fresh sample was used for each test. Ink samples were placed on the plate of the rheometer. The cone is lowered up till the desired height and excess ink is trimmed from the gap. The gap between the cone and plate kept was 50 microns.

Flow curves of the inks were determined by conducting a shear rate sweep to determine the nature of the flow curve. The shear rate was increased from $0.1 \mathrm{~s}^{-1}$ to $50 \mathrm{~s}^{-1}$ for all 3 ink samples. To avoid wall slip during measurements, inks were not to subjected to higher shear rates beyond $50 \mathrm{~s}-1$. Also, high shear rates resulted into ink misting.

\subsection{Experiments conducted on Offset Machine}

Printing was done using a test chart as given in Fig. 3. The layout of test chart includes various patches of halftones starting from $10 \%$, $25 \%, 50 \%, 75 \%, 90 \%$ and solid patch of $100 \%$ and skin tone (portrait in the test chart) which was imaged using a thermal computer to plate technology. KBA Rapida was the offset press used and the speed of the machine used for experimentation was kept constant at 6000 copies per hour. Computer to plate (CTP) technology was used to prepare plates of the test chart

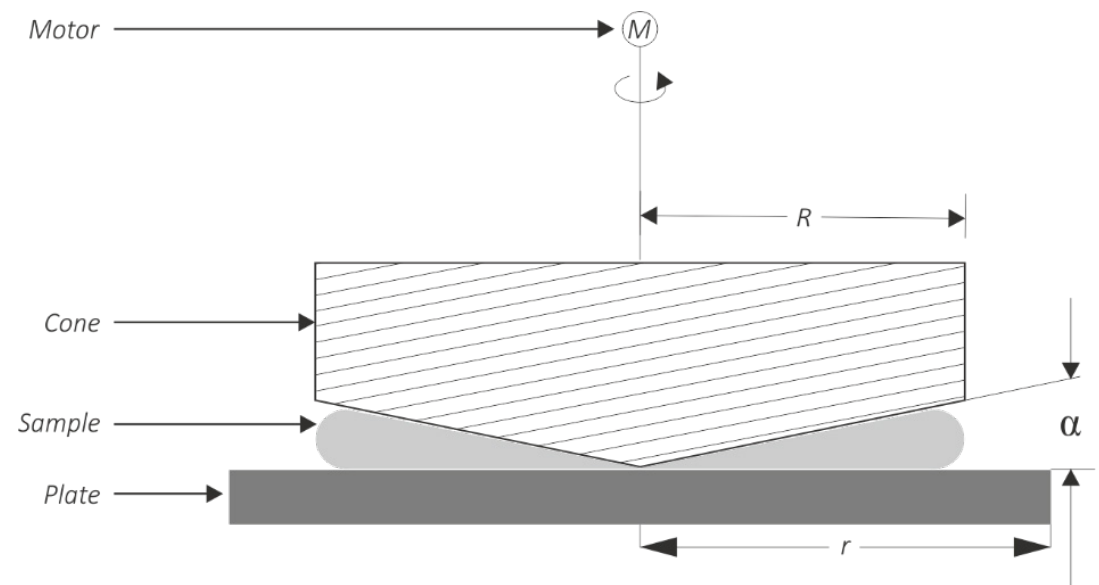

Fig. 2 Cone and plate geometry used in rheometer for rheology measurements 


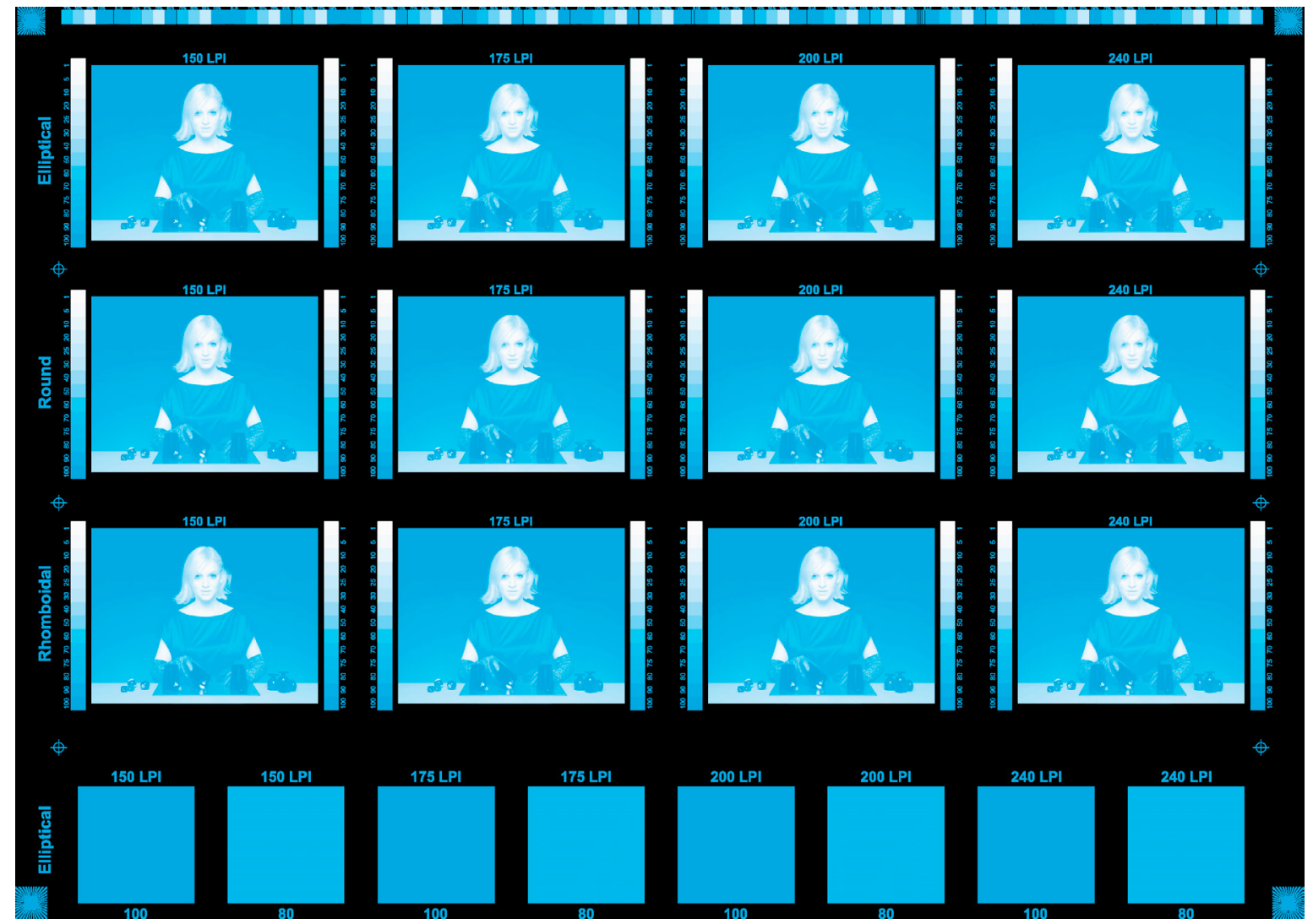

Fig. 3 Test chart with various elements used for print trials

to be printed. The halftone screening used was Amplitude Modulation (AM) using 150 line per inch screen frequency and an elliptical dot shape while making the CTP plate. In case of AM screening the size of the dots varies but the space between the dots is uniform. Machine room temperature was maintained at $23{ }^{\circ} \mathrm{C}$. The machine condition was constant for all trials. Each ink was printed separately using SBS sheets with a print density of 1.45 and sampled for evaluation of TVI at the halftone patches 10, 25, 50, 75, 90 and 100\% placed next to the image in test chart as shown in Fig. 3 using a Techkon SpectroDens Spectro-Densitometer.

Spectro-densitometer was used under D50 standard illumination, ISO E density filter with polarisation filter and $2^{\circ \circ}$ observer angle with measurement condition M0. The tone value increase was measured using the Spectro-Densitometer in the reflection mode. The total increase including increase due to mechanical and optical aspects were calculated by the Murray-Davies equation. The fountain solution was prepared with $\mathrm{pH} 5.3$ and percentage of Isopropyl Alcohol added was $6 \%$. The conductivity of raw water used was 100 micro siemens and conductivity of prepared fountain solution was 550 micro siemens. 15 experiments were conducted with 3 levels of ink and 5 levels of dot area. The experiments were conducted to correlate the behavior of 3 inks with varying viscosity and varying dot areas to TVI. The relationship of dot area and TVI and ink viscosity and TVI were analysed independently and was also analysed using ANOVA in Minitab ${ }^{\oplus}$ to study the combined effect of dot area and viscosity on TVI. As the objective of the experimentation was to analyse and correlate the effect of rheological characteristics to various dot area in print, other variables have not been included in this study. 


\section{Results and Discussion}

\subsection{Effect of Shear rate on viscosity - Steady state flow experiment}

The shear rate ramp is a frequently used test to measure the flow curve of any fluid. It is a rotational test. The apparent viscosity of inks decreases with the increase of shear rate.

All 3 inks in Fig. 4 exhibit shear thinning behavior. The graph indicates that the inks have different viscosities at low as well as high shear rates. Ink sample 1 shows lower viscosity than 2 and 3 at zero shear rate. The degree of shear thinning is different for all 3 inks. The presence of pigment particles in the vehicle affect the flow property of the polymer [28]. The inks indicate a flocculated nature exhibiting resistance to flow at low shear rates but their structure readily breaks down as shear rate increases [24]. It is expected that the viscosity of inks must be reduced for effective transfer of ink on the paper surface, but very high rate of shear thinning results into print quality problems such as extension of dot physically. Hence a good structure of ink at high shear rates gives better print quality. Ink sample 1 and 2 show similar lowest viscosity at high shear rates and is slightly higher for sample 3 . The rheology modifiers such as fumed silicas and clay are fine particle sized solid powders which are added in the ink samples 2 and 3 that help in increasing the viscosity of the inks. Ink sample 2 has higher percentage of clay than 3 . It shows that it increases the initial viscosity but is more shear thinning than sample 1 and 3 . Whereas addition of silica in sample 3 helps in controlling the shear thinning. Controlling shear thinning at high press speeds helps in controlling the dot spread. Rheology modifiers play a key role in inks rather than just increasing the viscosity. They help in modifying the rheology, stability of storage etc. [30].

\subsection{Tone Value Increase (TVI) as function of dot area at constant viscosity}

There are a number of factors affecting TVI. Increase in TVI, results into distortion of tone and color reproduction [31]. Printing machines run at high speeds during production process. The breakdown of ink structure at high shear rate causes the thickness of ink film to reduce as it eventually gets applied on the paperboard. For sample 1 and 2, lower shear stress is required to break down the flocculation and a lower ink viscosity thus will exhibit more spreading [25]. The prints samples were measured for optical density, dot gain, using a Techkon Spectro-densitometer. From Fig. 5 , it is seen inks 1 and 2 have high dot gain whereas ink 3 has lower TVI. There is a strong

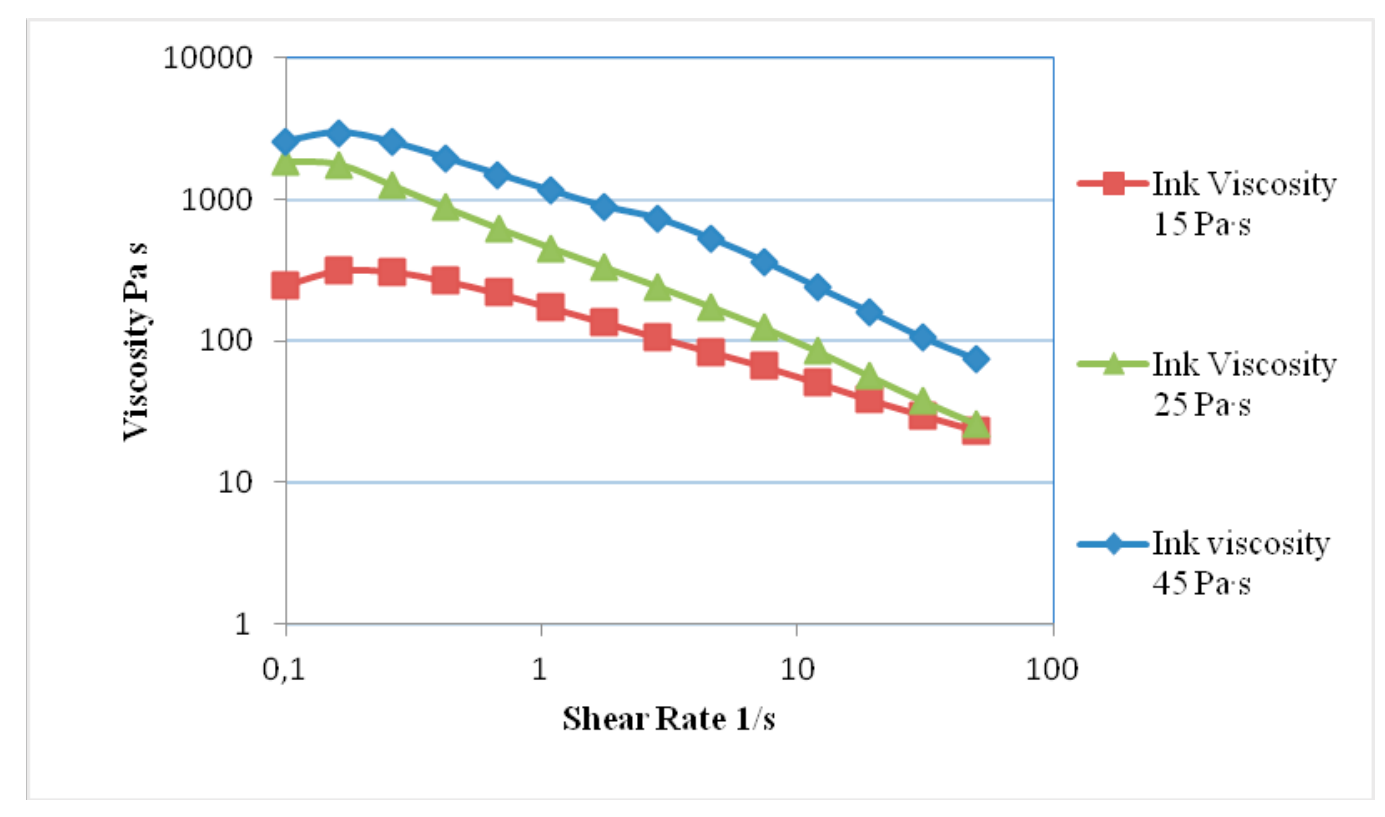

Fig. 4 Flow curve of 3 inks 


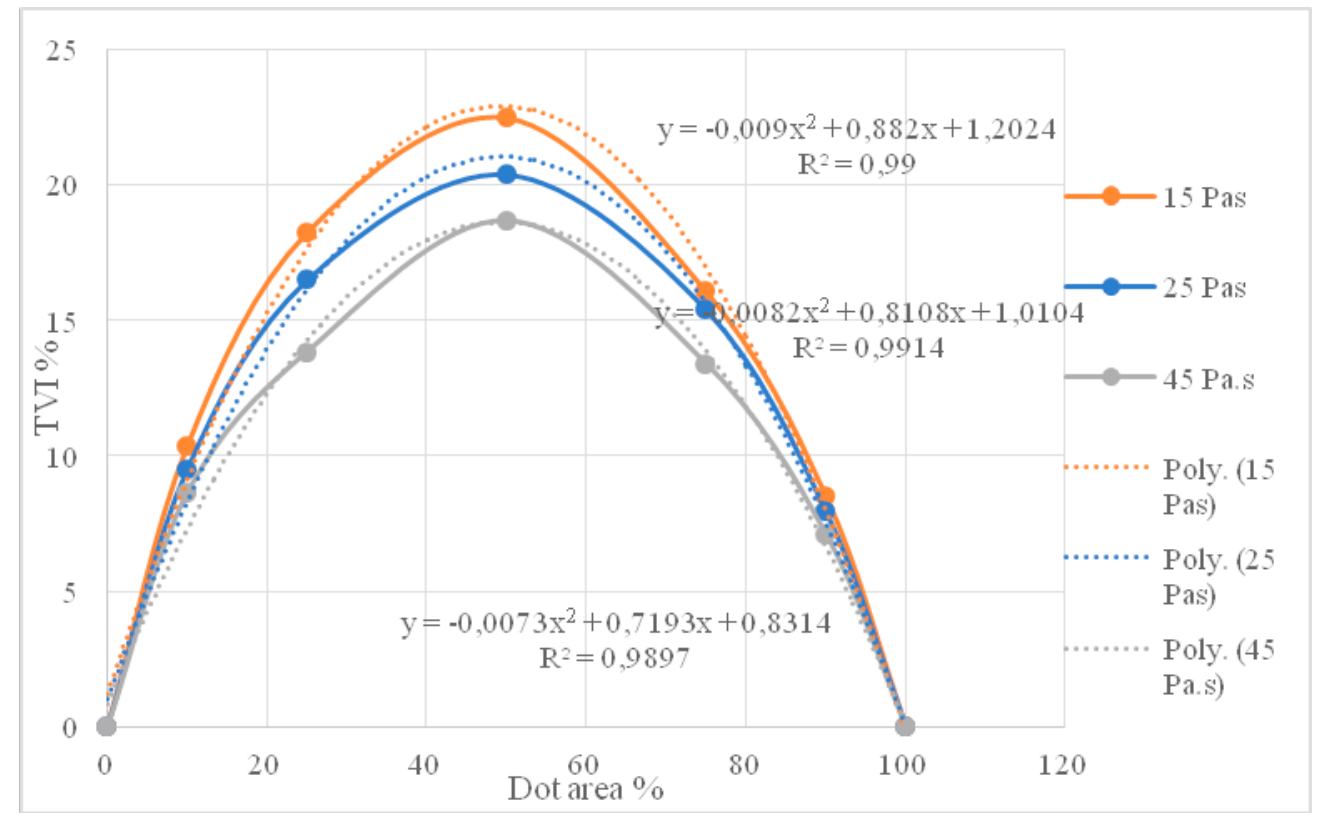

Fig. 5 Parabolic curve of dot area and TVI for 3 inks

correlation between ink viscosity and TVI as it can be seen that as viscosity has changed from $15 \mathrm{~Pa} \cdot \mathrm{s}$ to $45 \mathrm{~Pa} \cdot \mathrm{s}$, size of the dot has reduced. Fig. 5 shows the relation between dot area and tone value increase in the halftone areas of 10 , $25,50,75$ and $90 \%$ for each of the 3 inks. The highlight (10\% and $25 \%)$, middle tone (50\%) and shadow areas (75\% and 90\%) of halftone patches are selected for data measurement and analysis which are a quick indication and representation of a printed image [27]. The relationship indicates that TVI varies significantly with dot area. Maximum TVI can be seen in the middle tone areas (50\%) and minimum TVI is observed in ink sample 3 . The graph of ink sample 3 in Fig. (5) shows the TVI in highlight as well as the shadow areas is lower than the curves of sample 1 and 2 . The halftones printed by ink sample 3 would be sharper and with minimum distortion. TVI varies with dot area and this can be seen by the parabolic relation between these parameters. A generalised parabolic equation is given in Eq. (1). The parabolic relation between dot area and tone value increase as seen from the graph can be due to the combined effect of physical and optical dot gain [26].
$Y=\alpha x^{2}+\beta x+\gamma$

Plotting values of ink viscosity vs $\alpha, \beta$ and $\gamma$ and substituting these values in the Eq. (1) gives the relation of tone value increase and dot area for the fixed parameter ink viscosity. The new equation is

$\begin{aligned} \text { TVI }= & (0.00006 \mathrm{i}-0.0097) \mathrm{a}^{2}+(-0.0053 \mathrm{i}+ \\ & 0.9543) \mathrm{a}+(-0.0119 \mathrm{i}+1.3513)\end{aligned}$

Where ' $i$ ' is the ink viscosity and ' $a$ ' is the dot area.

Substituting the values of ink viscosity and dot area in the Eq. (2) gives us the calculated values of tone value increase (TVI) in table 4. Although TVI essentially is dependent on paper's surface properties, ink rheology, machine condition that is a combination of physical and optical reasons. In our experimentation apart of ink viscosity, all other variables have been kept constant. From Fig. (5) it can be seen that the difference in the curves is primarily due to the change in the ink viscosity. 
Table 4 RMSE values of actual and predicted values of TVI as function of dot area at constant viscosity (Eq. 2)

\begin{tabular}{|c|c|c|c|c|}
\hline 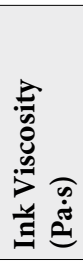 & 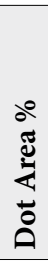 & 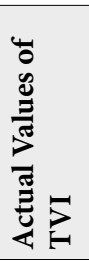 & 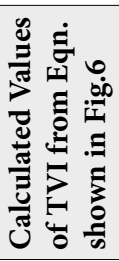 & \\
\hline 15 & 10 & 10.38 & 9.04 & 1.793 \\
\hline 15 & 25 & 18.26 & 17.54 & 0.514 \\
\hline 15 & 50 & 22.5 & 22.91 & 0.170 \\
\hline 15 & 75 & 16.08 & 17.28 & 1.446 \\
\hline 15 & 90 & 8.52 & 8.62 & 0.010 \\
\hline 25 & 10 & 9.52 & 8.45 & 1.141 \\
\hline 25 & 25 & 16.5 & 16.47 & 0.0006 \\
\hline 25 & 50 & 20.4 & 21.64 & 1.547 \\
\hline 25 & 75 & 15.4 & 16.56 & 1.354 \\
\hline 25 & 90 & 7.96 & 8.59 & 0.404 \\
\hline 45 & 10 & 8.64 & 7.27 & 1.866 \\
\hline 45 & 25 & 13.84 & 14.33 & 2.605 \\
\hline 45 & 50 & 18.68 & 19.10 & 0.568 \\
\hline 45 & 75 & 13.4 & 15.12 & 2.978 \\
\hline 45 & 90 & 7.12 & 8.5378 & 2.010 \\
\hline
\end{tabular}

\subsection{Tone Value increase as function of viscosity at a constant dot area}

Fig. 6 states the relation between ink viscosity and TVI at highlight, middle tone and shadow areas. Eq. (3) states that TVI varies with viscosity not linearly but with power. The coefficients in the equations at each of the dot areas are varying depending upon the dot area. The nature of all the Pa.s. s in the Eq. (3) for example at all tone areas gives the measured and predicted values of TVI.

The relation of ink viscosity and TVI in the mid-tone areas (50\%) as a case to understand is given in Eq. (3).

$y=29.398 x^{-0.115}$

Root mean squared value $=0.613$

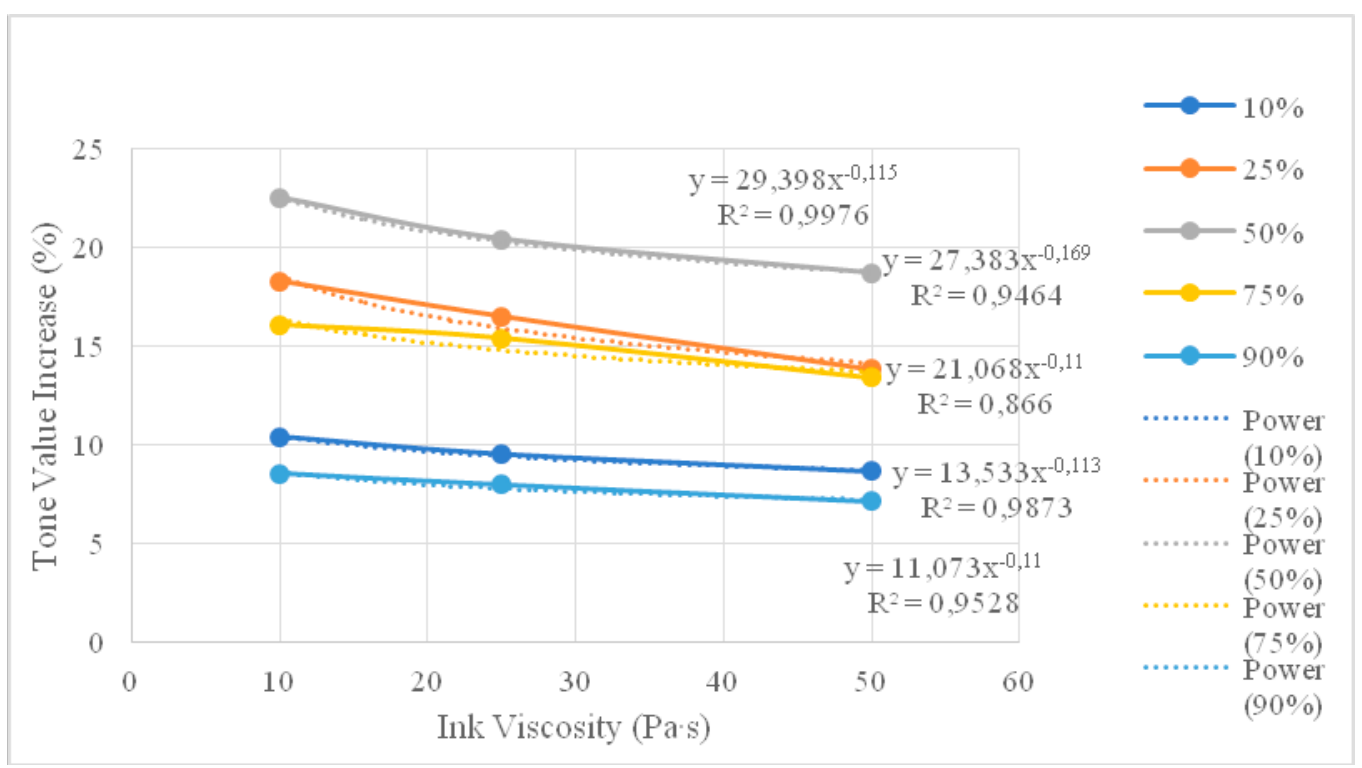

Fig. 6 Effect of ink viscosity on TVI at constant dot area 
Table 5 Actual and predicted values of TVI as a function of ink viscosity at constant dot area as calculated from Eq. (3)

\begin{tabular}{|c|c|c|c|c|}
\hline 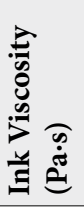 & 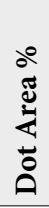 & 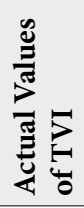 & 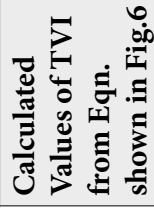 & \\
\hline 15 & 10 & 10.38 & 9.96 & 0.171 \\
\hline 15 & 25 & 18.26 & 17.32 & 0.870 \\
\hline 15 & 50 & 22.5 & 21.52 & 0.951 \\
\hline 15 & 75 & 16.08 & 15.64 & 0.193 \\
\hline 15 & 90 & 8.52 & 8.22 & 0.089 \\
\hline 25 & 10 & 9.52 & 9.40 & 0.012 \\
\hline 25 & 25 & 16.5 & 15.89 & 0.367 \\
\hline 25 & 50 & 20.4 & 20.29 & 0.010 \\
\hline 25 & 75 & 15.4 & 14.78 & 0.377 \\
\hline 25 & 90 & 7.96 & 7.77 & 0.035 \\
\hline 45 & 10 & 8.64 & 8.80 & 0.026 \\
\hline 45 & 25 & 13.84 & 14.39 & 2.430 \\
\hline 45 & 50 & 18.68 & 18.96 & 0.792 \\
\hline 45 & 75 & 13.4 & 13.86 & 0.211 \\
\hline 45 & 90 & 7.12 & 7.28 & 0.027 \\
\hline
\end{tabular}

Root mean squared error $=0.218$

Table 5 indicates the TVI for all dot areas using different equations for the dot areas. RMSE values indicate a good fit of actual and predicted values from the equation and the relation shows that TVI varies with ink viscosity.

\subsection{Tone Value increase as function of viscosity and dot area combined analysed statistically by ANOVA}

Table 6 ANNOVA Table for Response Surface Regression: TVI versus Ink Viscosity (Pa.s), Dot area in \%, Paper type

\begin{tabular}{|l|c|c|c|c|c|}
\hline Source & DF & Adj SS & Adj MS & F-Value & P-Value \\
\hline Model & 3 & 360.987 & 120.329 & 992.74 & 0.000 \\
\hline Linear & 2 & 20.143 & 10.071 & 83.09 & 0.000 \\
\hline $\begin{array}{l}\text { Ink Vis- } \\
\text { cosity } \\
\text { Pa.s }\end{array}$ & 1 & 9.011 & 9.011 & 74.34 & 0.000 \\
\hline $\begin{array}{l}\text { Dot area } \\
\text { in \% }\end{array}$ & 1 & 11.132 & 11.132 & 91.84 & 0.000 \\
\hline Square & 1 & 340.844 & 340.844 & 2812.04 & 0.000 \\
\hline $\begin{array}{l}\text { (Dot area } \\
\text { in \%) }\end{array}$ & 1 & 340.844 & 340.844 & 2812.04 & 0.000 \\
\hline Error & 11 & 1.333 & 0.121 & & \\
\hline Total & 14 & 362.320 & & & \\
\hline
\end{tabular}

Table 7 Model Summary for TVI for 3 inks and SBS paper type

\begin{tabular}{|c|c|c|c|}
\hline S & R-sq & R-sq(adj) & R-sq(pred) \\
\hline 0.348151 & $99.63 \%$ & $99.53 \%$ & $99.34 \%$ \\
\hline
\end{tabular}

The regression equation for is given as below:

TVI $=-0.007651 \mathrm{a}^{2}-0.06214 \mathrm{i}+0.7362 \mathrm{a}$

$$
+5.286
$$

The ANOVA table 6 indicates all the main factors are significant as all the ' $\mathrm{p}$ ' values are less than $a$ value is lower than 0.5 . Higher value of coefficient of determination (R-sq. 99.63\%) of variability can be explained by the ANOVA model at $95 \%$ confidence interval are shown in table 7. The Eq. (4) gives a relationship of TVI on dot area and ink viscosity combined. The actual and predicted values of TVI calculated from the Eq. (4) has been summarised for the 3 inks and different dot area percentages in Table 8 .

Table 8 Actual and predicted values of TVI as a function of ink viscosity and dot area calculated from Eq. (4)

\begin{tabular}{|c|c|c|c|c|}
\hline 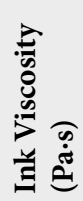 & 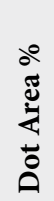 & 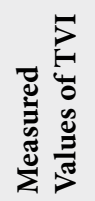 & 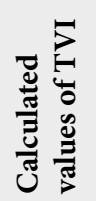 & 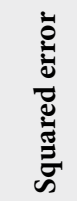 \\
\hline 15 & 10 & 10.38 & 10.95 & 0.325 \\
\hline 25 & 10 & 18.26 & 17.97 & 0.080 \\
\hline 45 & 10 & 22.5 & 22.03 & 0.214 \\
\hline 15 & 25 & 16.08 & 16.53 & 0.204 \\
\hline 25 & 25 & 8.52 & 8.63 & 0.014 \\
\hline 45 & 25 & 9.52 & 10.32 & 0.655 \\
\hline 15 & 50 & 16.5 & 17.35 & 0.732 \\
\hline 25 & 50 & 20.4 & 21.41 & 1.030 \\
\hline 45 & 50 & 15.4 & 15.91 & 0.260 \\
\hline 15 & 75 & 7.96 & 8.01 & 0.003 \\
\hline 25 & 75 & 8.64 & 9.08 & 0.199 \\
\hline 45 & 75 & 13.84 & 16.11 & 0.026 \\
\hline 15 & 90 & 18.68 & 20.17 & 0.097 \\
\hline 25 & 90 & 13.4 & 14.66 & 1.607 \\
\hline 45 & 90 & 7.12 & 6.77 & 0.119 \\
\hline
\end{tabular}

Root mean squared error $=0.371$ 


\section{Validation of Models}

The model developed through parabolic curve equation at constant viscosity, the model developed between ink viscosity and TVI at constant dot area and regression equation from ANOVA have been validated after comparison of the actual measured data and calculated TVI from the equation 2, 3 and 4. Fig. 7, 8 and 9 show a correlation coefficient higher than 0.9 in all the 3 mathematical relations established. The TVI extracted from the 3 different models correspond accurately to values of TVI obtained from the printing machines during the trials and satisfy the objective of establishing a correlation between ink rheology and TVI, an important characteristic useful to evaluate the increase in the physical dot gain in printing.

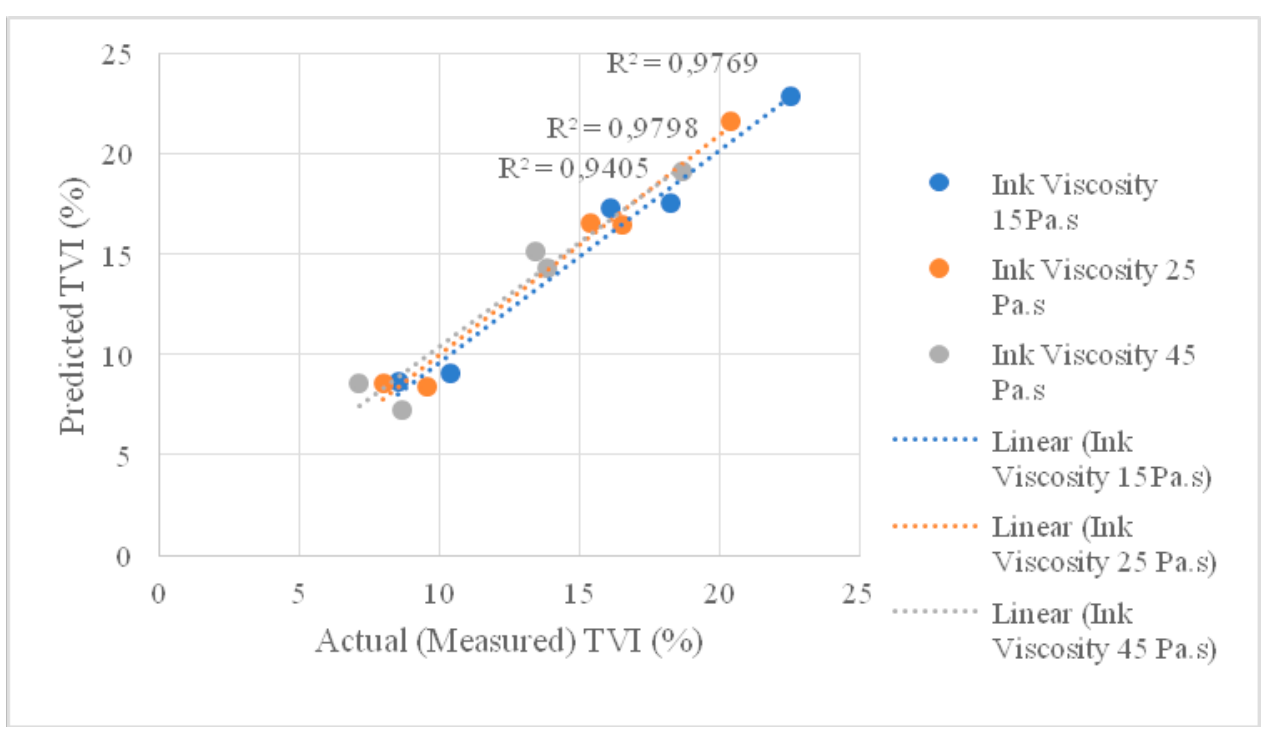

Fig. 7 Actual and predicted TVI values for 3 inks using equation (2)

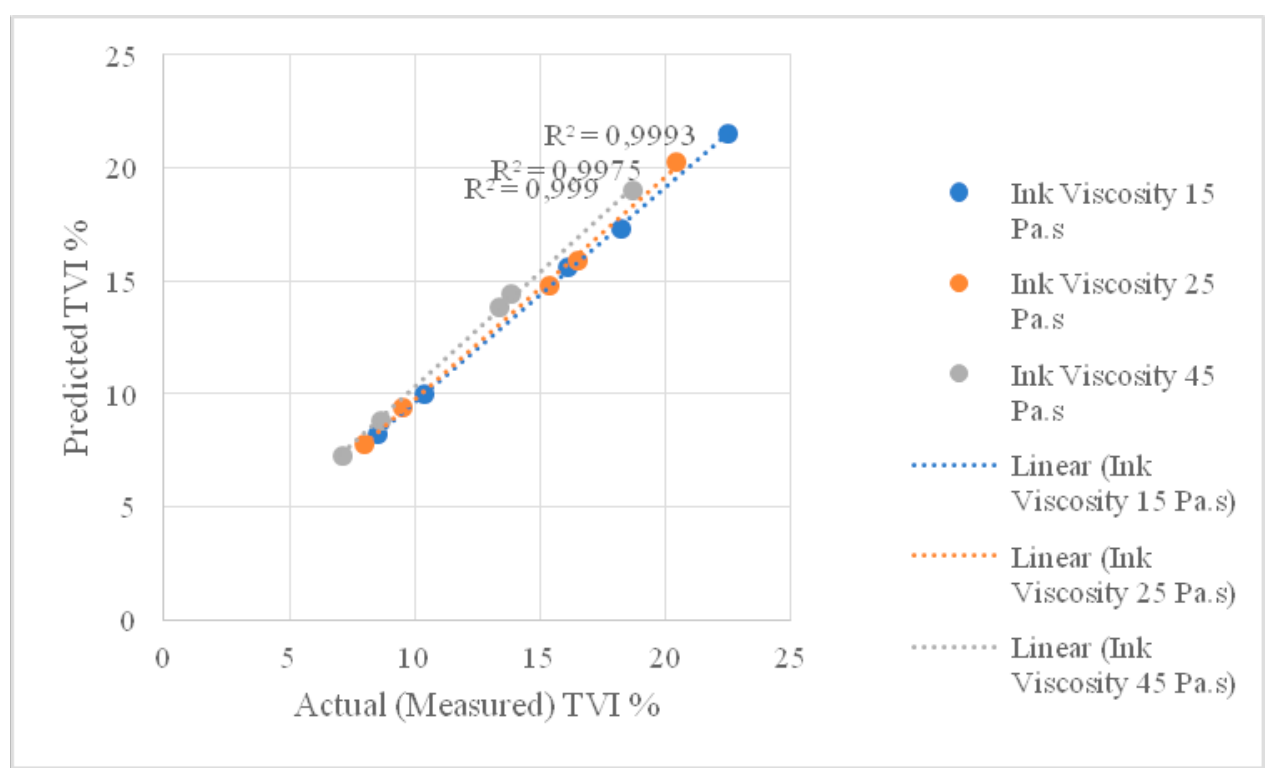

Fig. 8 Actual and predicted TVI values for 3 inks using equation (3) 


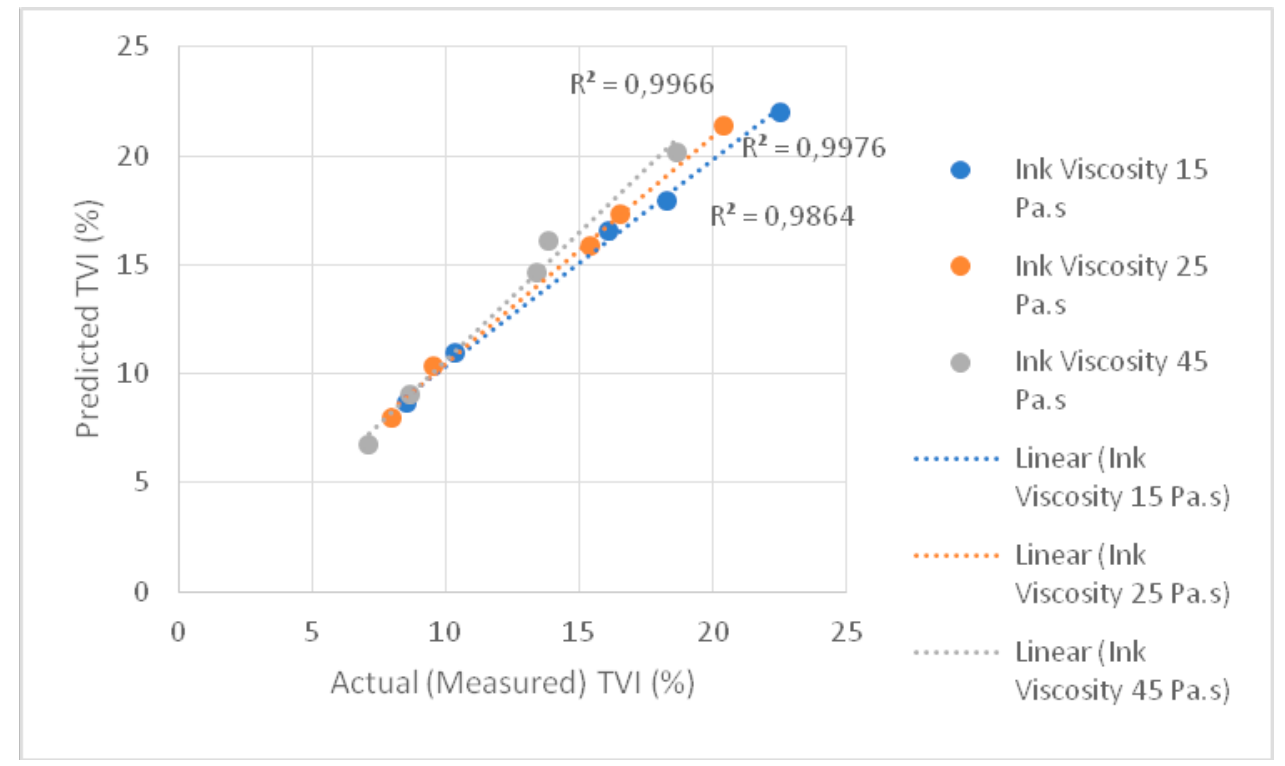

Fig. 9 Actual and predicted TVI values for 3 inks using equation (4)

\section{Conclusion}

The relation of ink viscosity and tone value increase was analysed for different halftone areas. Both ink viscosity and halftone areas have significant impact on the tone value. The mathematical relations between ink viscosity and dot area and dot area vs TVI was analysed independently and in a combined effect. Results from the stress ramp test indicate shear thinning behavior is prominent with inks having higher concentration due to addition of various rheology modifiers. Ink sample 2 and 3 contain clay and fumed silica. It can be seen clay appears to increase the initial viscosity in sample 2 but is more shear thinning than remaining of the ink samples. Whereas presence of silica in sample 3 has helped in controlling the shear thinning and consequently has resulted into lowest tone increase. The highlight areas at $25 \%$ and middle tone areas at $50 \%$ have greater impact on the tone value increase due to change in the viscosity. The total gain is attributed to physical increase in dimension due to spread of ink which occurs due to changes in ink flow and the optical increase in dot size results due to paper. As the type of paperboard is only of a single type, the differences in dot spread are attributed to ink viscosity. With the help of the 3 models developed, the physical increase in size of dot can be predicted if paperboard is kept constant. The study shall help ink manufacturers to characterise the inks in terms of flow behavior on the machine to produce sharp prints. This research will also help printers to select ink with appropriate viscosity to be able to print with controlled TVI as desired by print buyers. With good knowledge of relation of ink behavior and print results, this will help in reducing waste due to accurate print results.

\section{Acknowledgements}

The authors are grateful to Mr. S.S. Kulkarni of Huber Group for sponsoring the inks and necessary technical support. Also, they would like to thank Emami Paper Mills Ltd. for supplying the paperboard.

\section{References}

1. Kipphan, Helmut, ed., "Handbook of print media: technologies and production methods.", Springer Science \& Business Media, (pp. 89-90), (pp. 207-208) (2001) https://doi.org/10.1007/978-3-540-29900-4

2. Yang, Li. "A unified model of optical and physical dot gain in print color reproduction.", Journal of imaging science and technology, 48 (4) 347-353 (2004)

3. Bernd Th. Grande, Dot Gain in Offset Printing https://www.dod.uni-wuppertal.de/fileadmin/_migrated/content_uploads/Dotgain_in_Offset_Printing.pdf

4. Pangalos, G., Dealy, J.M, and Lyne, M.B., "Rheological Properties of News Inks", Journal of Rheology (J RHEOL), 29 (4) 471-491 (1985) https://doi. org/10.1122/1.549803

5. S. Mani, G. S. Grover, S. G. Bike, "Linear viscoelastic behavior of copper phthalocyanine dispersions used 
in printing inks", Rheologica Acta, 35 (4) 329-336 (1996) https://doi.org/10.1007/BF00403533

6. Askew, F. A., "Rheology in relation to the flying of printing inks.", Rheologica Acta, 4 (4) 285-288 (1965) https://doi.org/10.1007/BF01973672

7. Barnes, H.A., Thixotropy a review, J., "Non-Newtonian Fluid Mech.", scientific research, 70 1-33 (1997) https://doi.org/10.1016/S0377-0257(97)00004-9

8. Alias, Rosidah, and Sabrina Mohd Shapee., "Rheological behaviors and their correlation with printing performance of silver paste for LTCC tape.", In Rheology. InTech, (2012) https://doi.org/10.5772/35004

9. Jewell, E. H., Claypole, T. C., \& Gethin, D. T., "Viscosity control in the screen printing of ceramic transfers., Surface Coatings International Part B: Coatings Transactions, 86 (2) 155-163 (2003) https://doi. org/10.1007/BF02699628

10. Hayashi, T., Morita, K., and Amari, T., "Rheological properties and printabilities of polybutadiene/carbon black ink., Shikizai Kyokaishi, 66 (11) 655-664 (1993) https://doi.org/10.4011/shikizai1937.66.655

11. M. Fernández, M. E. Muñoz, A. Santamaría, R. Azaldegui, R. Díez et al, "Rheological analysis of highly pigmented inks: Flocculation at high temperatures", Journal of Rheology, 42 (2) 239-253 (1998) https:// doi.org/10.1122/1.550948

12. Z Wang, X Wang, T Fang, "The rheology of the offset inks", Surface Coatings International, 81 (5) 219-222 (1998) https://doi.org/10.1007/BF02693862

13. Bohumil Jašúrek, Jan Vališ, Tomáš Syrový, Bohuslav Jablonovský, "Study of Rheological Properties and Tack of Offset Printing Inks", International circle, (4) 18-23 (2011)

14. Kindernay, J., J. Panák, and M. Mikula. "Rheoviscometry of offset inks and their emulsions with water.", CHEMICAL PAPERS-SLOVAK ACADEMY OF SCIENCE, 55 (1) 15-22 (2001)

15. Durairaj, R., S. Ramesh, S. Mallik, A. Seman, and N. Ekere., "Rheological characterisation and printing performance of $\mathrm{Sn} / \mathrm{Ag} / \mathrm{Cu}$ solder pastes.", Materials \& Design, 30 (9) 3812-3818 (2009) https://doi. org/10.1016/j.matdes.2009.01.028

16. Armelin, Elaine, Mireia Martí, Elisabet Rudé, Jordi Labanda, Joan Llorens, and Carlos Alemán., "A simple model to describe the thixotropic behavior of paints.", Progress in organic coatings 57 (3) 229-235 (2006) https://doi.org/10.1016/j.porgcoat.2006.09.002

17. Jia, Xiao Xue, Bei Qing Huang, and Xian Fu Wei. "Study on the Influence of Rheological Properties on the Printing Quality of Ink., Advanced Materials Research, 284 2018-2021 (2011) https://doi. org/10.4028/www.scientific.net/AMR.284-286.2018

18. Barnes, H. A., "The yield stress-a review or " $\pi \alpha v \tau a$ $\rho \varepsilon$ '- everything flows?", Journal of Non-Newtonian
Fluid Mechanics, 81 (1-2) 133-178 (1999) https://doi. org/10.1016/S0377-0257(98)00094-9

19. Phair, J. W., Lundberg, M., \& Kaiser, A., "Leveling and thixotropic characteristics of concentrated zirconia inks for screen-printing.", Rheologica acta, 48 (2) 121-133 (2009) https://doi.org/10.1007/s00397-0080301-4

20. Barnes, H.A., A Handbook of Elementary Rheology, Institute of Non-Newtonian Fluid Mechanics, Aberystwyth, University of Wales, UK (2000)

21. Mackley, M. R., R. T. J. Marshall, J. B. A. F. Smeulders, and F. D. Zhao. "The rheological characterization of polymeric and colloidal fluids.", Chemical Engineering Science, 49(16) 2551-2565 (1994) https://doi. org/10.1016/0009-2509(94)E0082-2

22. Franck, A. "Understanding rheology of structured fluids., Book of TA instruments, 1-17 (2004)

23. Aucklah, Roshan. "Ink formulation and rheological characterisation of zirconia screen printing inks.", PhD diss., () Roshan Aucklah, (2011)

24. Leach, Robert. The printing ink manual. Springer Science \& Business Media, (2012)

25. Lin, C., \& Chung, D. D. L., "Nanostructured fumed metal oxides for thermal interface pastes.", Journal of Materials Science, 42(22) 9245-9255 (2007) https:// doi.org/10.1007/s10853-007-1911-4

26. Chang, S. A Dot-gain Analysis of Inkjet Printing. In DPP2001: International Conference on Digital Production Printing and Industrial Applications (5) (2001).

27. Dharavath, H. N., Bensen, T. M., \& Gaddam, B., "Analysis of print attributes of amplitude modulated (am) vs. frequency modulated (fm) screening of multicolor offset printing.", Journal of Industrial Technology, 21 (3) (2005)

28. Hosseini, Seyed Saeid, Arjomand Mehrabani-Zeinabad, and Ali Zadhoush. "The effect of carrier molecular weight and pigment particle concentration on the rheological properties of suspension systems in polymeric medium., behavior, 57 (2007)

29. Murray, H. H. (1999). Applied clay mineralogy today and tomorrow. Clay minerals, 34(1), 39-49.

30. Mai, R., Pekarovicova, A., \& Fleming, P. D., "Rheology modifiers in water-based rotogravure inks", Technical Association of the Graphic Arts, TAGA, 580591 (2006)

31. Hsieh, Yung-Cheng. "Factors Affecting Dot Gain on Sheet-Fed Offset Presses." Journal of Visual Communications. University of Houston, Houston, TX, 3952 (1997)

32. Rousu SM, Gane PA, Eklund DE. Influence of coating pigment chemistry and morphology on the chromatographic separation of offset ink constituents. In 12th Fundamental Research Symposium, FRC-Oxford, UK (2001 Sep 17). 